\title{
Study on Affixed New Words in Chinese Based on Memetics
}

\author{
Gaimei Zhao \\ Xi'an Peihua University, Xi'an 710125, China \\ 1142626982@qq.com
}

\begin{abstract}
Keywords: Meme; Affixed New Words.
\end{abstract}
\begin{abstract}
A meme is an information pattern, held in an individual's memory, which is capable of being copied to another individual's memory. Memes are the basic building blocks of our minds and culture, in the same way that genes are the basic building blocks of biological life. Memetics is the theoretical and empirical science that studies the replication, spread and evolution of memes. If the contagious nature of memes is brought to bear upon popular words, it will, for sure, strengthen the study of the propagation of messages. Based on the meme theory, this paper explores that affixed new words resemble parasites in the way that they are copied and transmitted quickly, which have the following characteristics: dynamic, high frequency and derivational. From a certain point of view, affixed new words express people's values, ideas and state of mind and reflect the social phenomenon. It is hoped that the present paper may give readers some insight in exploration of the spread of affixed new words and draw attention of more people from different field of study.
\end{abstract}

\section{Introduction}

This is a changing age in which great changes have taken place in many aspects of people's life, including their conception of the world, mode of thinking, their lifestyle and many others. However all such varieties are expressed by the language - the most important tool for the human communication. Affixed new words are coming towards us in an uncontrolled way, which are the most active and sensitive components to show great changes in social culture. Compared with the ordinary words, the study of the phenomenon of affixed new words has much more linguistic and social-cultural values.

Richard Dawkins, a famous Oxford zoologist, first coins the word meme in his best-selling book the Selfish Gene in 1976, in which he holds natural selection does not proceed the species or the group, or even the individual, but the genes. He believes that the sole function of a replicator is to be copied and genes are an example of such a replicator. He called ideas or behaviors copied from one person to another replicators or memes, which conveys the idea of a unit of cultural transmission and sounds a bit like gene [1].

Because people spreading memes continue to carry memes, this transmission can be understood as a copy process, that is, a copy of a meme in the memory of another person, making the person a meme host. The host must have the ability to articulate the meme and perform cognitive tasks related to meme, which means that only the man can serve as a host. Meme, as a cultural gene, survives by copying and spreading, and language is one of its carriers. Memetics studies the theory of memes replication, propagation, and evolution. Affixed new words express people's values, ideas and state of mind and reflect the social phenomenon. It is hoped that the present paper may give readers some insight in exploration of the spread of affixed new words and draw attention of more people from different field of study.

\section{Study on Affixed New Words}

\subsection{Phenomenon of Affixed New Words.}

Along with the political scandal "the Watergate event" in the early 1970s, a group of derived words have emerged in the lexicon such as "Billygate", "Cattlegate", "Debategate," "Irangate", "Ricegate", "Whitewatergate"[2].Under this circumstance, a sociolinguistic study of affixed new words is 
necessary to examine the semantic, structural and functional development of these words. After a careful study of this phenomenon, we found that the affix has a rich productivity in English and Chinese and that such a cultural phenomenon can be explained in detail under the framework of memetics.

Since the reform and opening to the outside policy, lot of affixed new words come into being in Chinese. Though Chinese lack of strict morphological changes, there are some obvious affix. Now, we have enough evidence that the affixed new words are a major trend of neologism.

Susan Blackmore [3] points out when the information model can be spread, the imitation becomes a meme. For example, the character “吧” (bar) initially in English, took root in China in the 1930s, and now it sprouts new buds, referring to all recreational places. People use the “-吧” meme to reflect their leisure life in communication: 酒吧 (bar) / 迪吧 (disco bar) /书吧 (book bar) / 布吧 (cloth bar) / 陶吧 (pottery bar) / 网吧 (internet bar).

Once people find that the new word patterns can meet the needs of communication, the new meme will be reproduced widely. Susan Blackmore thinks that meme theory is closely related with the language. Meanwhile she points out human beings are very different from other animals not because of their bigger brains but because of their grasp of imitation ways. In the process of verbal communication, Chinese people form a new “ -族(group of people)” meme: “丁克族(DINK)、打工族(working class)、追星族(idolater)、手机族(people with mobile phone)、持卡族(card holders)、工薪族 (wage earners)" which shows more and more different groups in our modern life. [4]. These affixed new word memes, derived from the common words and are easy to understand, have the strong ability to be reproduced and transmitted. Replication makes the rapid development of such words and affixed new words become one of the main trends in neologism [5].

\subsection{Characteristics of Meme Theory.}

The wide spread of affixed new words are the results of meme drive, which is inherited like a gene and spreads like a virus from one mind to another, especially by imitation. The following is the lifecycle of the meme [6] .

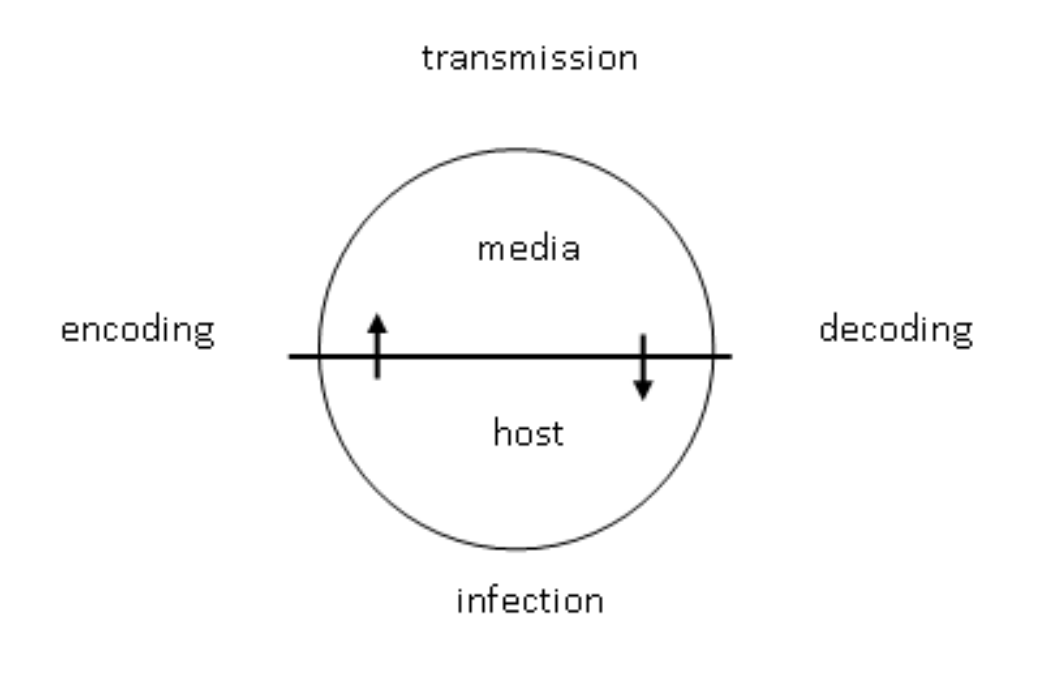

Fig. 1 lifecycle of the meme

As is shown in the chart, meme is encoded in the media in the transmission course. When the host decodes the meme, it may become active and infects the person, who will become the new host. People also find the way in which an affixed new word becomes popular. Successful memes are good at exploiting the environmental factors while unsuccessful meme will be washed out. Whichever stage the lifecycle is interrupted at, the spread of memes will be influenced. Meme theory provides us with a good theoretical framework for explaining the affixed new word and its spreading. In the process of becoming popular, affixed new words may undergo transmission stage, decoding stage and infection stage just as memes do. 
Decoding is the stage when a possible host explains and restructures the information by understanding, and thus produces a mental copy of the meme. The possibility of infection appears after decoding. Many of these decoding processes are subconscious. If a host is unable to understand the meme, the meme will not proceed to infection stage. Therefore newspapers and magazines are seen to attract the possible host in different ways.

A person who does not remember a meme at all is not infected. A person whose behavior is affected by a meme has been actively infected and can possibly transmit it to the other hosts. For example, the character “绿色(green) ” meme comes from phrase “绿色食品(green food)”. People know the connotation of the green here means being healthy. Then people choose some relative words to indicate what they want, such as 绿色蔬菜(green vegetable), 绿色教育 (green education), 绿 色开发 (green development), 绿色牛奶(green milk), 绿色治疗 (green treatment), 绿色消费(green consumption), 绿色科技(green science and technology).

If the infected host forgets the meme before he has spread it, the host has not done the meme any good. Thus successful memes encourage changes in the host for a long time. The hosts just change their behaviors in a way that will promote the transmission of the meme. From the phrases “非常话 题 (hot topic)”, people analogy such patterns like “非常展览 (unique show), 非常柠檬 (beverage), 非常男女(Tv programme), 非常夏日(film), 非常可乐 (cola)” [7]. However the affixed new word meme here means "unusual or quite different". It is the quite different use that makes the language meme prevalent.

When there is the change in society, great changes will take place in the language, especially in lexicon. Affixed new words, which can be found everywhere in our life, pass on the strong spirit of the time and the social culture in the transformation. Compared with all the samples, the author acknowledges that the affixed new words have the following characteristics: dynamic, high frequency and derivational.

Affixed new words are dynamic. Every affix undergoes the same process: being produced, becoming popular, being ignored and becoming unpopular, being forgotten or assimilated as part of the common language. There are but two ends for the affixed new words: disappearing, that is being eliminated in practical use; or being accepted into the daily vocabulary [8]. After being repeated too much, the affixed new words will become plain, even stereotyped. Then these words will be discarded or be replaced by fresher ones. Affixed new words can only stay popular within a certain period of time. Once these patterns are introduced and spread, they will be used and accepted by people in a social group as frequently as possible. However, different people use affixed words in different ways in accordance with their age, occupation, sex, education and way of talking.

Affixed new words are derivational. That is to say, they may change their forms to mean more than the original. Ever since the words which are related to Olympics are popular in the media, Chinese have more affixed new words with “奥运 (Olympic Games)” such as奥运精神 (Olympic spirit), 人 文奥运(People friendly Olympics), 科技奥运 (high-tech Olympics), 绿色奥运 (green Olympics)”。

In Chinese, more and more morphemes are taking the roles of affixations, with the increasing number of loan words and words created by analogy to familiar words. Affixed new words must correspond with the culture and psychology in the society. These words not only replicate the successfully spreading word forms but also make innovations in the structure. With the successful show of the TV play 《爱你没商量》, a lot of words turn to be popularwith the similar structure. Here is just some of them: “骗你没商量(someone cheated)”，“赚你没商量(someone cost more)” , “用你没商量(someone exploited)” and etc.

The spread of such memes is based on the rapid development of media and people's tolerance to the new phenomenon. The affixed new word, as a dynamic opening system, is closely related with people's lives, reflecting the transformation of the society. Once new things and new concepts appear, the new words will come into being in the language and the formation of words occur accordingly. These words memes become popular quickly because people are always seeking for the appropriate way to express their feelings and experience. Therefore these affixed new words express the certain 
sociocultural condition of the time frame. For example, people give priority to the modern technology and some words formed by “高 (high)”, “超(super)”, are used to describe new things. The following affixed new words come into being: “高技术 (high technology), 高风险 (high risk), 高消 费(high consumption), 高档次( high-class), 高品位(high taste); 超市 (supermarket), 超豪华 (super luxury), 超高速 (super high-speed)” [9].

\subsection{Explanation of Tendency of Affixed New Words.}

Affixed new words are indicators of the development and change of the society. The great number of corresponding affixed new words reflects that the rapid development of science and technology. Chinese new words are closely related to the development of China in the past years since China's policy of reform and opening to the outside world. The certain society will give birth to certain new words. We can also follow the development tendency of the society by tracking these new words. Language is the basic form of human communication. We do communicate through some non-verbal forms like gestures, facial expressions and others, but the culmination of true communication is through language. In this sense, we cannot communicate in any real sense without language.

Affixed new words are widely used and quickly spread in a certain period of time, in a given area or among a particular group. In a certain sense, these words express people's values, ideas and state of mind and can reflect the social structure and value system of a community. Since new words are a mirror of social life, we can learn about the culture of the time and place by an investigation into the words which are popular in that society. New words are indicators of the development and change of a society, as is universal to all cultures. A certain society will give birth to certain new words which can help us trace the development and changes taking place in that society. Understanding affixed new words should be based on knowing about the background of the time.

Language can also be seen as a media for spreading memes. Meme theory describes the ways in which beliefs spread, persist, and recede. The basic principles of meme theory can account for the rise and fall of numerous widespread new words and hundreds of other memes. The popularity period of new words is mostly from one to five months. Meme theory provides us with a good theoretical framework for explaining the nature of new words and how they spread [10]. Generally speaking, all new words undergo transmission stage, decoding stage and infection stage just like the meme communication. The success or failure of new word memes can tell us a lot about the society at the time.

From the memetic point of view, memes were born when humans began to imitate each other and imitation is the key to all human activities. When imitation became widespread, successful memes begin to use verbalizations for better and more frequent transmission. Affixed new words are successful memes, which will thrive and widely spread when they succeed in being copied. Today the vast majority of language memes are transmitted through direct speech, written communication, radio or television, and the internet. [11]

\section{Conclusion}

Memetics is a very hot topic in western countries. But in China, it hasn't received due attention. The present research introduces the meme theory into the study of affixed new words, with a hope to make more people know about the theory and apply it to their language research. Based on the meme theory, the paper proposes a conceptual framework for the analysis of affixed new words. These words reflect and influence people's life, which is transitory and subject to change. The spread of affixed new words is closely related with the new social cultural phenomenon and reflects the social phenomenon truthfully. Affixed word memes can be copied in a great variety of occasions from speech to speech, from paper to paper, from book to book, from computer to humans, from person to person, etc.

Memetics provides us a new perspective for social science research, especially for language research. The social function of a language determines how words develop together with society. Since language is dynamic, in the development of language, new memes in language will inevitably prosper so long as they can be widely imitated, quoted and transmitted, whether or not they have been 
entirely accepted by the orthodox grammar or by some other rules temporally. We have reasons to believe that, due to the replication and the spread of memes, many other new ways of expressing concepts or thinking will be on their way to language and, at the same time, will bring about great changes to language. It is just a matter of the fact that memes are constantly getting replicated and being passed on by imitation [12].

Memetics provides us a new insight to probe into the study of language. In terms of language memes, not only a new word can be a meme, a slogan, brand names, advertising images can also become memes when they are capable of leading many imitators to repeat them through time. Moreover, memetics can surely go beyond the study of new word, extending to other genres of language [13]. We hope that the present research will draw due attention of researchers, helping them understand this particular cultural phenomenon. We also hope, with more and more people swinging in with the study of memes, memetics will obtain a more rapid development in China, especially in the field of linguistics.

Affixed new words are a brand of a generation because they can tell us about people's conception of new things. To affixed new words, we should keep an open mind. With the passing of time, words that are strong and powerful will remain while those that are weak will disappear automatically. Compared with the common words, affixed new words belong to the minority, which cannot shake the base of national culture. Affixed new words are the most sensitive to social changes and these words pop up in related newspapers and magazines, radio and TV programs, and net websites. However to a great extent, the phonology, lexicon and grammar of Chinese determine the formation and tendency of affixed new words.

We believe that further research remains to be done in the study of affixed new words under memetics. We feel that our attempt is only a beginning of the long-term study in the field. It is hoped that the paper may give our readers some insight in the study of popular culture and draw attention of more people from different field of study.

\section{References}

[1]. Dawkins, R. The selfish gene. Oxford University Press, 1976.

[2]. Rong Ren, Language and Translation (Chinese) Vol, 2. 2004

[3]. Blackmore, S. The meme machine. Oxford University Press, 1999.

[4]. Nairong Qian. Study on Neologism at 21st Century. Journal of Shanghai University, Social Science Edition.Vol, 9. 2002.

[5]. Changyou Li. Source and Development Tendency of New Words in New Era. Vol, 4, Journal of Xuchang University. 2003

[6]. Henrik Bjarneskans, Bjarne Grunevik and Anders Sandberg. The Lifecycle of Memes [EB- 01].

[7]. Ying Zhang, Lianxiang Ma. Brief Study on Popular Words. Academic Communication.2003

[8]. Song Jing. Probe into Popular Words. Chinsese Construction.1999

[9]. Hongxi Liu. Research into Neologism. Chongqing Technology and Business University (Social Science Edition). Vol, 3. 2004

[10]. Gaimei Zhao, Xiaobin Wang. Study on meme and popular words. Journal of Xi'an International Studies University. Vol, 2. 2007

[11]. Ziran He. Meme in the Language. Proceedings in the 2nd Pragmatics Research in China. 2004

[12]. Meiying Zhuang: Advertising Slogans as Strong Memes- an analysis of Pragmatics and Memes in Language (Master, Guangdong University of Foreign Studies, China, 2005)

[13]. Keqi Xu, Yuanzhuo Qu. Meme Research in 30 Years. Jiangsu Foreign Language Teaching and Research. 2011 